\title{
Spectrophotometric Determination of Trace Iron by Using Its Catalytic Effect on the $N$-Phenylanthranilic Acid-Potassium Periodate Reaction
}

\author{
Angelina M. Stoyanova \\ Department of Chemistry and Biochemistry \& Physics and Biophysics, Medical University-Pleven, \\ Pleven 5800, Bulgaria
}

\begin{abstract}
The analytical features of the reaction between $N$-phenylanthranilic acid (PAA) and potassium periodate in acidic medium are explored with the aim of improving the catalytic kinetic determination of iron in water samples. In the presence of Fe(II, III), PAA is oxidized by potassium periodate in a formic acid medium to form a violet-colored compound. The reaction is followed spectrophotometrically by measuring the increase in the absorbance of the oxidation product at 525 $\mathrm{nm}$. The variables that affected the reaction rate were investigated and the reaction conditions were established. Calibration graphs are linear in the range of concentrations $2-500 \mathrm{ng} \mathrm{mL}^{-1}$. As low as $10^{-8} \mathrm{~mol} \mathrm{~L}^{-1} \mathrm{Fe}$ (II, III) can be easily determined by the fixed time method. The established catalytic method was successfully applied to the determination of iron in tap water and in pharmaceutical samples.
\end{abstract}

(Received August 28, 2007; Accepted November 5, 2007; Published May 10, 2008)

\section{Introduction}

The role of iron as a trace element in biologic systems is well established. It is an essential component or cofactor of numerous metabolic reactions. Every living cell in both plants and animals contains iron. It is involved in oxygen transport and electron transfer and in enzymes including hydroxylases, peroxidases and dismutases. ${ }^{1}$ Iron deficiency anemia is one of the world's most common nutritional deficiency diseases. Evidence has been presented that at low levels iron is an essential element in the diet, whereas at higher concentrations it is toxic. ${ }^{2}$ High iron level in drinking water, in addition to its toxicity, can result in poor taste and in staining of laundry, glassware and dishes. Large quantities of iron are widely distributed throughout the environment. Thus, because of its toxicity, determining the iron content in drinking water is of considerable interest. Natural water sources usually contain low concentrations of iron but some ground water sources may contain considerably more iron.

A number of sensitive analytical methods are available for the determination of iron. At present some of the most commonly used methods include spectrophotometry, ${ }^{3-5}$ chemiluminescence,,${ }^{6,7}$ fluorescence analysis,${ }^{8}$ polarographic and voltammetric analysis,, 910 flow-injection analysis, ${ }^{6,11-13}$ atomic emission and atomic absorption spectrometries ${ }^{14-16}$ and others. ${ }^{17,18}$ Various kinetic methods based on the catalytic action of iron on the oxidation of organic compounds have been reported in several reviews ${ }^{19-21}$ and original papers. ${ }^{13,22-25}$ Among the many sensitive techniques for iron determination, kinetic catalytic methods are worth special mention on account of their high sensitivity and simple and low-cost equipment. ${ }^{26}$ Developing of novel simple kinetic procedures, carried out at an

E-mail: astoy@abv.bg easily maintained temperature for a short reaction time, is still needed from the practical point of view.

This paper describes a new, simple and accurate catalytic spectrophotometric method for the determination of iron, based on its catalytic effect on the reaction between $\mathrm{N}$ phenylanthranilic acid and potassium periodate in formic acid medium. By this method, total iron concentrations can be determined in the range of $2-500 \mathrm{ng} \mathrm{mL}^{-1}$ with detection limit of $0.88 \mathrm{ng} \mathrm{mL}^{-1}$. The proposed method was successfully applied to the determination of iron in tap water and pharmaceutical samples.

\section{Experimental}

\section{Reagents}

All solutions were prepared from analytical-reagent grade chemicals and doubly distilled water. The laboratory glassware was treated with an alkaline solution, and then kept in $\mathrm{HCl}(1: 1)$ overnight, followed by rinsing with distilled and doubly distilled water.

A stock $\mathrm{Fe}(\mathrm{III})$ solution $\left(\approx 0.1 \mathrm{~mol} \mathrm{~L}^{-1}\right)$ was prepared by dissolving $\approx 7 \mathrm{~g}$ of $\mathrm{FeCl}_{3} \cdot 6 \mathrm{H}_{2} \mathrm{O}$ (Merck) in $250 \mathrm{~mL}$ of $2 \mathrm{~mol} \mathrm{~L}^{-1}$ $\mathrm{HCl}$ (Merck). Its exact concentration was determined gravimetrically. Working solutions were prepared daily by appropriate dilution with water. An Fe(II) stock solution (0.1 mol L-1) was prepared by dissolving $1.9883 \mathrm{~g}$ of $\mathrm{FeCl}_{2} \cdot 4 \mathrm{H}_{2} \mathrm{O}$ (Merck) in $10 \mathrm{~mL}$ of $1 \mathrm{~mol} \mathrm{~L}^{-1}$ hydrochloric acid, and diluting to $100 \mathrm{~mL}$ with water. Working solutions were prepared by appropriate dilution of this solution with water. $\mathrm{N}$ Phenylanthranilic acid (PAA, Merck) stock standard solution (0.01 mol L $\left.\mathrm{L}^{-1}\right)$ was prepared by dissolving the reagent in concentrated formic acid (98\%, Merck). The use of formic acid is necessary in order to accomplish the dissolution of PAA and to fulfill the requirement of a highly acidic medium without any 


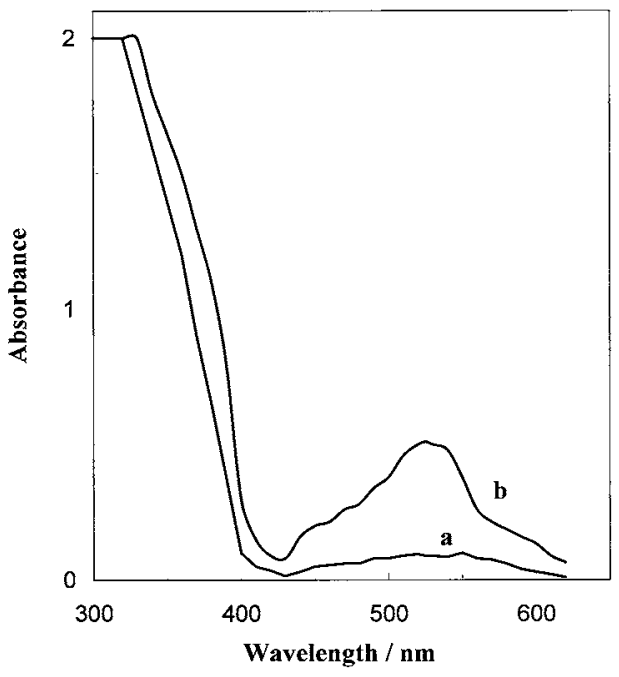

Fig. 1 Absorption spectra of the reaction product. (a) In the absence of the catalyst, (b) in the presence of $112 \mathrm{ng} \mathrm{mL}^{-1} \mathrm{Fe}(\mathrm{III})$. Conditions: $6 \times 10^{-4} \mathrm{~mol} \mathrm{~L}^{-1} \mathrm{KIO}_{4} ; 10 \times 10^{-4} \mathrm{~mol} \mathrm{~L}^{-1} \mathrm{PAA}$; time, 15 min; $35^{\circ} \mathrm{C}$; formic acid medium.

other buffering reagent. A $0.015 \mathrm{~mol} \mathrm{~L}^{-1}$ solution of potassium periodate was prepared by dissolving $0.3451 \mathrm{~g} \mathrm{KIO}_{4}$ (Fluka) in $100 \mathrm{~mL}$ of water. An ascorbic acid water solution $\left(0.01 \mathrm{~mol} \mathrm{~L}^{-1}\right)$ was prepared as a masking agent.

\section{Apparatus}

Absorbance measurements were made on both a Jenway 6505 UV/Vis (England) and a Specol 11 (Germany) spectrophotometers fitted with $1-\mathrm{cm}$ cells. The spectrophotometer cell compartments were thermostatted by means of circulating water. A TB 120 thermostat (Germany) was used to bring the reagents to the desired temperature. The acidity of the reaction mixtures in the preliminary experiments was controlled by using a $\mathrm{pH}$-meter inoLab pH720 (Germany).

\section{Procedure}

All the solutions were preheated to the working temperature of $35^{\circ} \mathrm{C}$ in a thermostat bath. To a series of $10 \mathrm{~mL}$ volumetric flasks, $7.8-8.2 \mathrm{~mL}$ of concentrated formic acid were introduced and $1 \mathrm{~mL}$ of PAA stock solution was added. For the catalyzed reaction aliquots of less than $0.8 \mathrm{~mL}, \mathrm{Fe}(\mathrm{III})$ solution containing 20 - $5000 \mathrm{ng} \mathrm{mL}^{-1}$ iron were added. The mixture obtained was shaken and $0.4 \mathrm{~mL}$ of $0.015 \mathrm{~mol} \mathrm{~L}^{-1}$ potassium periodate was added. The zero time was taken as the moment at which the last drop of potassium periodate had been added. The solution was made exactly to the volume of $10 \mathrm{~mL}$ with formic acid, mixed and immediately transferred into a $1-\mathrm{cm}$ constant temperature cell at $35^{\circ} \mathrm{C}$. The rate of indicator reaction was followed spectrophotometrically using the fixed time procedure. The absorbance was measured at $525 \mathrm{~nm}$ against water exactly 15 min from the initiation of the reaction. The noncatalyzed reaction was monitored in the same way using blank solution.

\section{Analysis of water samples}

Collected samples were analyzed within $24 \mathrm{~h}$ after filtration (with Whatman No. 40). Tap water samples $(100 \mathrm{~mL})$ were acidified with $10 \mathrm{~mL}$ of conc. $\mathrm{HNO}_{3}$ and evaporated nearly to dryness in a fume cupboard in order to dissolve the salts and to release bound iron to free iron ions. The evaporation is necessary to destroy organic matter and to avoid matrix
Table 1 Analytical data for the determination of Fe(III) by fixed time method

\begin{tabular}{llll}
\hline \multirow{2}{*}{ Parameter } & \multicolumn{3}{c}{ Reaction time/min } \\
\cline { 2 - 4 } & \multicolumn{1}{c}{10} & \multicolumn{1}{c}{15} & \multicolumn{1}{c}{20} \\
\hline Slope $/ \times 10^{-3}$ & 2.234 & 4.151 & 4.482 \\
Intercept & 0.060 & 0.094 & 0.137 \\
Detection limit/ng $\mathrm{mL}^{-1}$ & 1.58 & 0.88 & 1.94 \\
\hline
\end{tabular}

Conditions: $6 \times 10^{-4} \mathrm{~mol} \mathrm{~L}^{-1} \mathrm{KIO}_{4} ; 10 \times 10^{-4} \mathrm{~mol} \mathrm{~L}^{-1} \mathrm{PAA} ; 35^{\circ} \mathrm{C}$; formic acid medium.

interferences. Then the dry residue was heated with $10 \mathrm{~mL}$ of doubly distilled water; the resulting solution was cooled, quantitatively transferred into a $50 \mathrm{~mL}$ calibrated flask and, after addition of $0.5 \mathrm{~mL}$ of $0.01 \mathrm{~mol} \mathrm{~L}^{-1}$ ascorbic acid, made up to the mark with doubly distilled water. An aliquot of thus treated water sample was used for iron determination according to the recommended procedure.

\section{Analysis of pharmaceuticals}

The proposed method was applied to the analysis of iron in pharmaceutical samples, ampoules with iron solution for oral administration. A $1.0 \mathrm{~mL}$ aliquot of the sample was diluted with water in a $100 \mathrm{~mL}$ volumetric flask, and then the iron content was determined using the procedure described above.

\section{Results and Discussion}

\section{Effect of reaction parameters}

$N$-Phenylanthranilic acid and its derivatives are used as precursors for the synthesis of pharmaceuticals, especially nonsteroidal anti-inflammatory drugs such as Mefenamic acid and Flufenamic acid. ${ }^{27,28}$ PAA was applied as a specific reagent for the detection of nitrite and nitrate anions in a sulfuric acid medium. ${ }^{29}$ It has been used in analytical chemistry as a redox indicator, having a redox potential of $1.08 \mathrm{~V}$ referred to the hydrogen electrode..$^{30}$ As an aromatic amine, it forms intensively colored reaction products, which contributes to the sensitivity of the reaction with spectrophotometric monitoring.

The preliminary experiments showed that the oxidation of PAA by potassium periodate in acidic medium yields a violetcolored product. The reaction was slow, but it was sharply increased by the addition of trace amounts of iron, $\mathrm{Fe}(\mathrm{II})$ and $\mathrm{Fe}$ (III) showed the same catalytic effect. The absorption spectra of the reaction products are presented in Fig. 1. As can be seen, the greatest difference between the absorbances of the catalyzed and the noncatalyzed reaction occurred at $525 \mathrm{~nm}$. Therefore, in further studies the process was monitored spectrophotometrically by measuring the increase in absorbance at $525 \mathrm{~nm}$ versus time.

The influences of the reaction variables (reaction time, acidity, temperature, reagent concentrations) on the reaction rate were studied in the presence and absence of iron in order to establish the optimum reaction conditions. The system was optimized by altering each variable in turn, while the others were kept constant.

The effect of the reaction time was studied in the range $10-20$ min. The intercept, slope and detection limit were evaluated by linear regression analysis of the calibration graphs constructed by plotting absorbance versus concentration of $\mathrm{Fe}$ (III) at fixed times of 10, 15 and $20 \mathrm{~min}$. The most acceptable values of the intercept, slope and detection limit were obtained at a fixed time of $15 \mathrm{~min}$ (Table 1). As a measurement of the initial reaction 


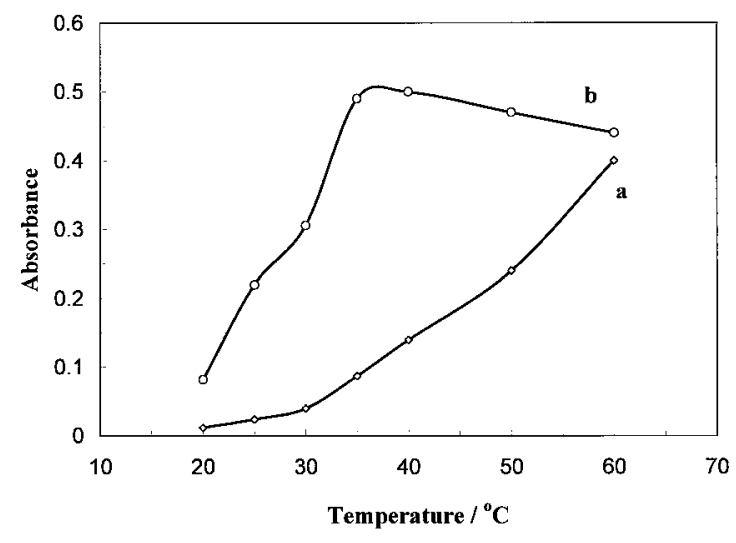

Fig. 2 Effect of temperature on the reaction rate. (a) Noncatalytic reaction, (b) in the presence of $112 \mathrm{ng} \mathrm{mL}^{-1} \mathrm{Fe}(\mathrm{III})$. Conditions: $6 \times$ $10^{-4} \mathrm{~mol} \mathrm{~L}^{-1} \mathrm{KIO}_{4} ; 10 \times 10^{-4} \mathrm{~mol} \mathrm{~L}^{-1}$ PAA; $525 \mathrm{~nm}$; time, $15 \mathrm{~min}$; formic acid medium.

rate, the fixed time of $15 \mathrm{~min}$ from the initiation of the reaction was selected.

PAA is insoluble in water but soluble in most organic solvents and in strongly acidic media. Initially, we dissolved it in ethanol and studied the reaction at different $\mathrm{pH}$ values (from 1.8 to 7.0 ), obtained by adding appropriate volumes of $0.2 \mathrm{~mol} \mathrm{~L}^{-1}$ sodium hydroxide to $100 \mathrm{~mL}$ of the three-component mixture of 0.04 mol L $\mathrm{L}^{-1}$ boric acid, phosphoric acid and acetic acid. The experiments with these buffer solutions showed that, at very low or higher (above $\mathrm{pH} 2$ ) $\mathrm{pH}$ values, the observed reaction rate dramatically decreases. A potassium chloride-hydrochloric acid buffer $\left(0.1 \mathrm{~mol} \mathrm{~L}^{-1}\right)$ was also applied to the system in the $\mathrm{pH}$ interval from 1 to 2 . The catalytic effect of $\mathrm{Fe}$ (III) in all cases was not appreciable, especially at higher $\mathrm{pH}$ values. That is why we dissolved DPA in another solvent, concentrated formic acid, which is miscible with water and most polar organic solvents. The reaction rate increased significantly, especially when the reaction was carried out in concentrated formic acid medium. Additional volumes of strong acids, such as $\mathrm{HCl}, \mathrm{H}_{2} \mathrm{SO}_{4}$ and $\mathrm{HNO}_{3}$, were added in order to check whether strong acidity accelerates the reaction. The addition of strong acids led to a suppression of the absorbance level and a decrease in the observed reaction rate. These experiments showed that the reaction should be carried out in strong acidic medium and in this medium formic acid is the best in sensitivity. The effect of formic acid concentration was tested in the concentration range of $2.4-23.9 \mathrm{~mol} \mathrm{~L}^{-1}$. The reaction rate of both catalyzed and noncatalyzed reactions increased with increasing formic acid concentration. It was experimentally confirmed that the reaction proceeds faster without buffer solutions; high concentrations of formic acid (above ca. $22.6 \mathrm{~mol} \mathrm{~L}^{-1}$ final concentration) ensure the best sensitivity and constancy of the $\mathrm{pH}$ in the reaction mixture. That is why in further studies the reaction was performed in concentrated formic acid medium.

The influence of the temperature was studied between 20 and $60^{\circ} \mathrm{C}$ (Fig. 2). The sensitivity increased with temperature up to $40^{\circ} \mathrm{C}$ in the presence of iron and decreased at higher temperatures. This behavior at temperatures higher than $35^{\circ} \mathrm{C}$ is due to a higher reaction rate of noncatalytic reaction compared to the rate of catalytic reaction. A temperature of $35^{\circ} \mathrm{C}$ was chosen as optimum since it provides a good reaction rate and low background and can be easily maintained.

Figure 3 reflects the influence of the potassium periodate concentration. The reaction rate increases with increasing

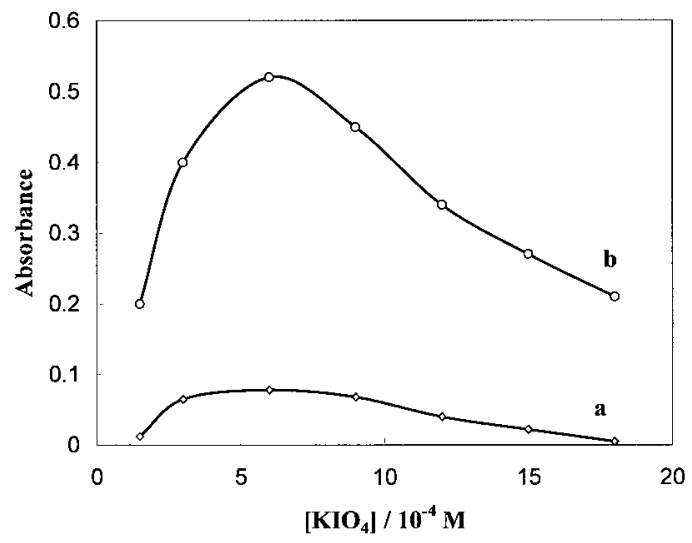

Fig. 3 Influence of $\mathrm{KIO}_{4}$ concentration on the reaction rate. (a) Noncatalytic reaction, (b) in the presence of $112 \mathrm{ng} \mathrm{mL}^{-1} \mathrm{Fe}(\mathrm{III})$. Conditions: $10 \times 10^{-4} \mathrm{~mol} \mathrm{~L}{ }^{-1}$ PAA; $525 \mathrm{~nm}$; $35^{\circ} \mathrm{C}$; time, $15 \mathrm{~min}$; formic acid medium.

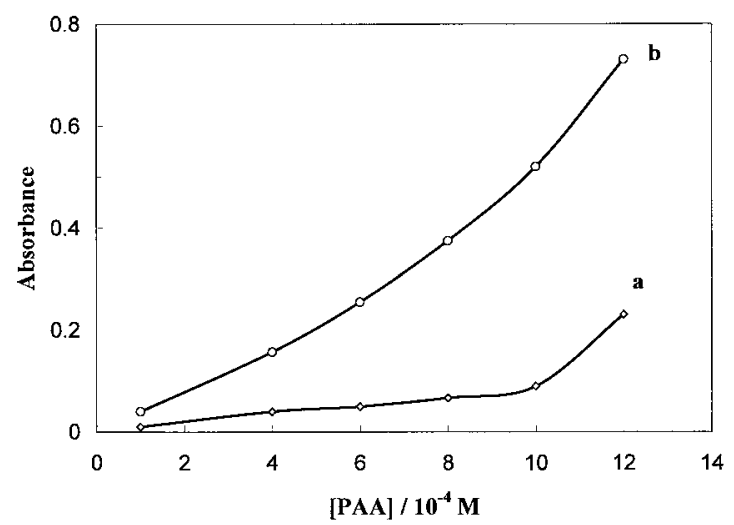

Fig. 4 Influence of PAA concentration on the reaction rate. (a) Noncatalytic reaction, (b) in the presence of $112 \mathrm{ng} \mathrm{mL}^{-1} \mathrm{Fe}(\mathrm{III})$ Conditions: $6 \times 10^{-4} \mathrm{~mol} \mathrm{~L}^{-1} \mathrm{KIO}_{4} ; 525 \mathrm{~nm} ; 35^{\circ} \mathrm{C}$; time $15 \mathrm{~min}$; formic acid medium.

potassium periodate concentration up to $6 \times 10^{-4} \mathrm{~mol} \mathrm{~L}^{-1}$. Higher concentrations do not increase the reaction rate, but instead a decrease is observed. Therefore the concentration of $6 \times 10^{-4} \mathrm{~mol} \mathrm{~L}^{-1}$ was chosen as the optimal one.

The effect of PAA concentration on the catalyzed and noncatalyzed reaction was investigated over the range $1-12 \times$ $10^{-4} \mathrm{~mol} \mathrm{~L}^{-1}$. The results reveal that the rates of both catalyzed and noncatalyzed reactions increased with increasing of PAA concentration. Since the effect was more pronounced for a catalyzed reaction, a higher sensitivity could be realized at higher PAA concentration (Fig. 4). A concentration of $10 \times 10^{-4}$ mol L ${ }^{-1}$ was finally selected by considering the sensitivity and reproducibility.

Considering the above experimental results and literature about the catalytic action of iron as $d$-element, ${ }^{26}$ one can assume the following probable reaction scheme:

$$
\begin{aligned}
& \mathrm{Fe}(\mathrm{III})+\mathrm{PAA} \longrightarrow \mathrm{Fe}(\mathrm{II})+\text { product } \\
& \mathrm{Fe}(\mathrm{II})+\mathrm{IO}_{4}^{-} \longrightarrow \mathrm{Fe}(\mathrm{III})+\mathrm{IO}_{3}{ }^{-} .
\end{aligned}
$$

The catalyst may interact with the substrate to yield a product by changing its oxidation state, from which it is regenerated upon subsequent reaction with the oxidant. For most catalytic 
Table 2 Effect of foreign ions on the determination of $112 \mathrm{ng}$ $\mathrm{mL}^{-1} \mathrm{Fe}(\mathrm{III})$

\begin{tabular}{cl}
\hline $\begin{array}{c}\text { Tolerance level, } \\
\text { [foreign ion]/[Fe(III)] }\end{array}$ & \multicolumn{1}{c}{ Foreign ion added } \\
\hline$>1000$ & $\mathrm{Na}^{+}, \mathrm{NH}_{4}{ }^{+}, \mathrm{Ca}^{2+}, \mathrm{Mg}^{2+}, \mathrm{Ba}^{2+}$ \\
500 & $\mathrm{Li}^{+}, \mathrm{Cd}^{2+}, \mathrm{Al}^{3+}, \mathrm{Zn}^{2+}, \mathrm{NO}_{3}^{-}, \mathrm{F}^{-}$, citrate \\
& tartrate, ascorbate $^{2}$ \\
& $\mathrm{Co}^{2+}, \mathrm{Ni}^{2+}, \mathrm{Mn}^{2+}, \mathrm{Cr}^{3+}, \mathrm{PO}_{4}^{3-}, \mathrm{Cl}^{-}, \mathrm{SO}_{4}^{2-}$ \\
& $\mathrm{C}_{2} \mathrm{O}_{4}^{2-}$ \\
50 & $\mathrm{Ag}^{+}, \mathrm{Cu}^{2+}, \mathrm{Bi}^{3+}, \mathrm{Mo}(\mathrm{VI})$ \\
30 & $\mathrm{Hg}^{2+}, \mathrm{SCN}$ \\
1 & $\mathrm{~V}(\mathrm{~V}), \mathrm{Cr}(\mathrm{VI})$ \\
\hline
\end{tabular}

reactions of this type, the first stage is rate-determining. ${ }^{20}$

The rate equation for the reaction studied could be expressed as follows:

$$
\text { Rate }=\mathrm{d} P / \mathrm{d} t=k[\mathrm{PAA}]\left[\mathrm{KIO}_{4}\right][\mathrm{Fe}(\mathrm{III})]+k_{\mathrm{o}}[\mathrm{PAA}]\left[\mathrm{KIO}_{4}\right]
$$

where $P$ is the concentration of the reaction product, and $k$ and $k_{\mathrm{o}}$ denote the rate constants of the catalytic and the noncatalytic reactions.

Assuming that the rate of noncatalytic reaction was very slow and that the concentrations of PAA and $\mathrm{KIO}_{4}$ are much greater than those of iron, Eq. (1) can be written as:

$$
\text { Rate }=\mathrm{d} P / \mathrm{d} t=k^{\prime}[\mathrm{Fe}(\mathrm{III})]
$$

where $k^{\prime}$ is conditional rate constant for the catalyzed reaction. Equation (2) was the quantitative basis for the determination of iron by the proposed method.

\section{Calibration graph and reproducibility}

Under the optimal reaction conditions described above two calibration graphs are obtained using the fixed time method: one for iron concentration in the range $2-200 \mathrm{ng} \mathrm{mL}^{-1}$ and the other for the range of $200-500 \mathrm{ng} \mathrm{mL}^{-1}$. The relevant equations and the coefficients of correlations of the two graphs are respectively:

$$
\begin{array}{ll}
A=0.094+0.00415[\mathrm{Fe}]\left(\mathrm{ng} \mathrm{mL} L^{-1}\right) & r=0.9953 \\
A=0.103+0.00232[\mathrm{Fe}]\left(\mathrm{ng} \mathrm{mL}^{-1}\right) & r=0.9906
\end{array}
$$

The relative standard deviations for ten replicate determinations of 24 and $112 \mathrm{ng} \mathrm{mL}-1$ of $\mathrm{Fe}(\mathrm{III})$ were 5.3 and $3.8 \%$, respectively. Since Fe(II) showed the same catalytic effect as $\mathrm{Fe}(\mathrm{III})$, the total iron concentration can be determined by the proposed method. The calibration graphs for Fe(II) were almost identical to those for $\mathrm{Fe}(\mathrm{III})$ in the same concentration range within the experimental error. The detection limit of this method was $0.88 \mathrm{ng} \mathrm{mL}^{-1}$, calculated as three times the standard deviation of the blank divided by the slope of the calibration graph.

\section{Interference studies}

To study the selectivity of the proposed method, we investigated the influence of foreign ions on the determination of $112 \mathrm{ng} \mathrm{mL}^{-1} \mathrm{Fe}(\mathrm{III})$. The tolerance limit was defined as the concentration at which the species caused an error of less than $\pm 5 \%$. The interferences are listed in Table 2. The results obtained indicate that almost all the common ions that are normally associated with iron in various types of samples, e.g.
Table 3 Determination of iron in real samples

\begin{tabular}{crcccc}
\hline Sample & $\begin{array}{c}\text { Added/ } \\
\text { ng mL }\end{array}$ & $\begin{array}{c}\text { Found/ } \\
\text { ng mL } \\
\text { mean } \pm \mathrm{SD}\end{array}$ & $\begin{array}{c}\text { RSD, } \\
\%\end{array}$ & $\begin{array}{c}\text { Recovery, } \\
\%\end{array}$ & $\begin{array}{c}\text { Standard } \\
\text { method/ } \\
\text { ng mL }^{-1}\end{array}$ \\
\hline Tap water & 0 & $38.1 \pm 1.1$ & 2.9 & - & 38.7 \\
1 & 20 & $57.5 \pm 1.3$ & 2.3 & 97.0 & \\
Tap water & 0 & $24.2 \pm 0.8$ & 3.2 & - & 23.4 \\
2 & 20 & $44.8 \pm 1.3$ & 2.9 & 103.0 & \\
Diluted & 40 & $63.7 \pm 1.3$ & 2.0 & 98.8 & \\
oral drops & 20 & $52.1 \pm 0.2$ & 3.8 & - & - \\
& 40 & $93.2 \pm 1.2$ & 1.3 & 102.8 & - \\
\hline
\end{tabular}

$n=5$.

mineral, industrial and biological samples, do not interfere with the determination of $\mathrm{Fe}(\mathrm{III})$. Only $\mathrm{Cr}(\mathrm{VI})$ and $\mathrm{V}(\mathrm{V})$ showed positive interferences in ratio $1: 1$ to iron. However, the interference from $\mathrm{V}(\mathrm{V})$ can be considered as being not serious, because its content is usually very low in natural waters. The interfering effect of $\mathrm{Cr}(\mathrm{VI})$ could be eliminated by reducing it to $\mathrm{Cr}(\mathrm{III})$ with ascorbic acid. It was estimated that ascorbic acid did not interfere with the determination of iron up to 500-fold excess, as shown in Table 2. The results in Table 2 demonstrate that this method has a good selectivity.

\section{Application}

The reliability of the present method was tested by determining the iron concentration in samples of tap water from Pleven region, Bulgaria. Iron concentration was determined by applying the calibration curve and standard addition methods. The results obtained by the present method were compared with those obtained by the standard procedure for the determination of total iron in water samples using 1,10-phenanthroline ${ }^{31}$ (Table $3)$.

The proposed method was also applied for the determination of iron in pharmaceutical samples, Tot'hema ampoules (Laboratoire Innotech International, France) with iron solution, containing according to the label $50 \mathrm{mg} / 10 \mathrm{~mL}$ ferrous gluconate, $1.33 \mathrm{mg} / 10 \mathrm{~mL}$ manganese gluconate, $0.70 \mathrm{mg} / 10$ $\mathrm{mL}$ cupric gluconate and as additives: glycerol, glucose, sucrose, citric acid, sodium benzoate, isoamyl acetate, isoamyl butyrate, benzaldehyde, gamma undecalactone, ethylvaniline, alcohol et al. A recovery study was carried out on samples to which definite amounts of iron standards were added (Table 3). Recovery tests for both, water and pharmaceutical samples, were satisfactory (about $97.0-104.0 \%$ ) with relative standard deviations of $1.2-3.8 \%$.

\section{Conclusions}

In this study, the catalytic effect of $\mathrm{Fe}(\mathrm{II})$ and $\mathrm{Fe}$ (III) on the oxidation of PAA by potassium periodate was studied. Since $\mathrm{Fe}(\mathrm{II})$ and $\mathrm{Fe}(\mathrm{III})$ showed the same catalytic effect, a new catalytic kinetic spectrophotometric method for the determination of total iron was developed. The method proposed is highly sensitive and simple, and the precision is very acceptable for the determination of low ranges of iron. With its detection limit of $0.88 \mathrm{ng} \mathrm{mL} \mathrm{m}^{-1}$, this method is comparable to analytical techniques with detection limits in the ng $\mathrm{mL}^{-1}$ range, such as atomic emission and atomic absorption 
spectrometries, and other procedures described in the cited references. The proposed method was successfully applied to the determination of iron in tap water. This method is also suitable for the analysis of iron in pharmaceuticals, because no interference from the excipients normally present in the commercial pharmaceutical samples was observed.

\section{References}

1. F. A. Cotton and G. Wilkinson, "Advanced Inorganic Chemistry", 1988, Wiley Interscience, New York.

2. A. Piperno, Haematologica, 1998, 83, 447.

3. T. N. K. Kumar and H. D. Revanasiddappa, Anal. Bioanal. Chem., 2003, 376, 1126.

4. C. D. Stalikas, A. C. Pappas, M. I. Karayannis, and P. G. Veltsistas, Microchim. Acta, 2003, 142, 43.

5. A. Niazi, Croat. Chem. Acta, 2006, 79, 573 .

6. K. Soitoh, T. Hosebe, N. Teshima, M. Kurihara, and T. Kawashima, Anal. Chim. Acta, 1998, 376, 247.

7. A. Waseem, M. Yaqoob, and A. Nabi, Luminescence, 2004, 19, 333 .

8. Z. Zeng and R. A. Jewsbury, Analyst, 2000, 125, 1661.

9. L. Yang, L. Wang, L. Lin, Z. Peng, and G. Lu, Anal. Sci., 2004, 20, 1655.

10. T. Nagai, A. Imai, K. Matsushige, K. Yokoi, and T. Fukushima, Limnology, 2004, 5, 87.

11. A. Tsuji, N. Teshima, M. Kurihara, S. Nakano, and T. Kawashima, Talanta, 2000, 52, 161.

12. A. A. Ensafi, M. A. Chamjangali, and H. R. Mansour, Anal. Sci., 2004, 20, 645.

13. S. Lunvongsa, M. Oshima, and S. Motomizu, Talanta, 2006, 68, 969.

14. L. Xia, Y. Wu, Z. Jiang, S. Li, and B. Hu, Int. J. Environ. Anal. Chem., 2003, 83, 953.

15. E. K. Paleologos, D. L. Giokas, S. M. Tzouwara-Karayanni, and M. I. Karayannis, Anal. Chim. Acta, 2002, 458, 241.

16. S. Tautkus, L. Steponeniene, and R. Kazlauskas, J. Serb. Chem. Soc., 2004, 69, 393.

17. H. Inoue and K. Ito, Microchem. J., 1994, 49, 249.

18. T. Sakai, M. Nakayama, T. Katami, and M. Furukawa, Microchim. Acta, 1989, 98, 31.

19. H. A. Mottola and D. Perez-Bendito, Anal. Chem., 1994, 66, 131R.

20. H. A. Mottola and D. Perez-Bendito, Anal. Chem., 1996, $68,257 \mathrm{R}$

21. S. R. Crouch and T. F. Cullen, Anal. Chem., 1998, 70, 53R.

22. T. Tomiyasu, N. Teshima, S. Nakano, and T. Kawashima, Talanta, 1998, 47, 1093.

23. A. Alexiev, S. Rubio, M. Deyanova, A. Stoyanova, D. Sicilia, and D. Pérez Bendito, Anal. Chim. Acta, 1994, 295, 211.

24. J. M. T. Carneiro, A. C. B. Dias, E. A. G. Zagatto, and R. S. Honorato, Anal. Chim. Acta, 2002, 455, 327.

25. S. Ohno, N. Teshima, H. Zhang, and T. Sakai, Talanta, 2003, 60, 1177.

26. D. Perez-Bendito and M. Silva, "Kinetic Methods in Analytical Chemistry", 1988, Ellis Horwood Ltd., Chichester.

27. D. R. Bauman, S. I. Rudnick, L. M. Szewczuk, Y. Jin, S. Gopishetty, and T. M. Penning, Mol. Pharmacol., 2005, 67, 60.

28. M. L. D. Palacios and R. F. P. Comdom, Synth. Commun., 2003, 33, 1771.

29. H. Chen, Y. Fang, A. Taicheng, K. Zhu, and J. Lu, Int. J. Environ. Anal. Chem., 2000, 76, 89.

30. W. S. Syrokomsky and V. V. Stepin, J. Am. Chem. Soc., 1936, $58,928$.

31. ISO 6332, "Water Quality-Determination of IronSpectrometric Method Using 1,10-Phenanthroline", 1988, International Organization for Standardization. 